University of Wollongong

Research Online

University of Wollongong in Dubai - Papers

University of Wollongong in Dubai

$1-1-2005$

\title{
Effects of electronic customer relationship management on customer
} satisfaction: a temporal model

Mohamed Khalifa

City University of Hong Kong, mkhalifa@uow.edu.au

Ning Shen

City University of Hong Kong, kathys@uow.edu.au

Follow this and additional works at: https://ro.uow.edu.au/dubaipapers

\section{Recommended Citation}

Khalifa, Mohamed and Shen, Ning: Effects of electronic customer relationship management on customer satisfaction: a temporal model 2005, 1-10.

https://ro.uow.edu.au/dubaipapers/202

Research Online is the open access institutional repository for the University of Wollongong. For further information contact the UOW Library: research-pubs@uow.edu.au 


\title{
Effects of Electronic Customer Relationship Management on Customer Satisfaction: A Temporal Model
}

\author{
Mohamed Khalifa \\ Ning Shen \\ Department of Information Systems \\ City University of Hong Kong \\ iskhal@cityu.edu.hk
}

\begin{abstract}
The proliferation of eCRM and its alarming failure rate call for a better understanding of the relationship between eCRM and its immediate objective: customer satisfaction. In this paper, we develop, operationalize and empirically test a temporal model explaining the relationship between three categories of eCRM (i.e., prepurchase, at-purchase and post-purchase eCRM) and online customer satisfaction at two phases of the customer lifecycle, i.e., attraction and retention. The results of a longitudinal survey of the online customers of hardware retailers provided strong support for the model and revealed the dominant role of pre-purchase eCRM in satisfaction formation at the attraction phase and the prevalence of post-purchase eCRM at the retention phase. Specific eCRM features are identified as satisfaction drivers, providing insights for important paradigm shifts.
\end{abstract}

\section{Introduction}

Until recently, most firms focused primarily on production, purchase and marketing. Their main concern was to provide products that satisfied their customers' first needs. In the past, such an approach was sufficient for most firms to survive and generate revenues. Nowadays, however, customers are more demanding more knowledgeable, and require more attention. Increasingly, firms are shifting their focus to the customer, hence the rising importance of customer relationship management (CRM). With the rapid growth of electronic business and proliferation of Internet-based services, a new concept is born: eCRM. It encompasses all the processes needed to acquire, build and maintain customer relationship through e-business operations. Important CRM concepts such as customization, personalization, making the customer less passive and more active, many-to-many marketing are either enabled or made easier to implement with eCRM tools. In fact, CRM remains just a philosophy devoid of concrete actions if not for these enabling tools. For instance, it is hard to imagine how to make it possible for customers to interact with each other without an online community. In addition to its enabling role, eCRM is also believed to be more convenient, more interactive, more efficient and providing a higher degree of customization. More importantly, the online channel is cheaper than the regular channels for both the firm and the customer.

The main driver for eCRM adoption seems to be a commonly shared belief that it improves customer loyalty and retention [1] through the enhancement of customer satisfaction. Researchers and practitioners alike are claiming positive effects of eCRM on customer satisfaction. However, no empirical evidence has been provided for these claims. In fact, a survey conducted by InfoWorld suggests that 77 percent of eCRM projects fail to meet company goals [2] and numerous studies cite the low rate of success of eCRM applications [3]. Even worse, Gartner [4] predicts that by 2006, more than 50\% of eCRM implementations will be considered as failures from a customer's point of view. Feinberg and Kadam's [5] survey suggests that eCRM failure may be due to the implementation of features that executives believe affect customer satisfaction, but in reality do not have any effect at all.

There is clearly a need to develop a better understanding of eCRM success. As customer satisfaction is one of the more immediate objectives of eCRM and as satisfaction is often used as a surrogate of success, a good way to study eCRM success is to examine the relationship between eCRM and customer satisfaction. Despite the great interest in elucidating the relationship between eCRM and customer satisfaction [6], prior research has not shed sufficient light on this relationship. Most previous studies focused on the effects of specific features of eCRM on satisfaction in isolation. The lack of a comprehensive model with a theoretical underpinning casts doubts about the interpretation of the empirical results of these studies. Furthermore, the very few studies attempting to develop a more complete model were crosssectional, providing little evidence of the effects of eCRM throughout the customer's lifecycle.

In this paper, we address this void. More specifically, we develop, operationalize and empirically test a temporal model explaining the effects of various types of eCRM features on customer satisfaction in the context of online shopping. Since success is goal dependent, it is important 
to distinguish between the two primary goals of eCRM, that is, customer attraction and customer retention. We therefore follow a longitudinal approach where we examine customer satisfaction in two separate phases of the customer lifecycle: attraction and retention.

Our research presents important theoretical and practical contributions. On the theoretical side, we build and validate a temporal model explaining the relationship between eCRM and customer satisfaction at the attraction and retention phases of the customer lifecycle. Our model addresses an important theoretical gap: the inability of existing models to explain eCRM success in general and the effect of eCRM on customer satisfaction in particular. On the practical side, we identify the main drivers of eCRM satisfaction and assess their relative importance. These results should help practitioners to prioritize their eCRM initiatives and to allocate resources accordingly.

This paper is organized as follows. We first review the literature on eCRM success and satisfaction. We then present the theoretical development and justify the research model. This is followed by a description of the research methodology and a discussion of the results. In conclusion, the implications of the results are discussed and future research directions are proposed.

\section{ECRM success}

Although an old concept, CRM has evolved in recent years to become the central strategy that provides seamless integration of different activities for anticipating, understanding, and meeting customer needs [7]. According to Sheng [8], the main objectives of CRM are the acquisition and retention of customers, leading to bottom-line financial benefits. The latest developments in Internet-based technology prompted the emergence of eCRM, enabling many innovations in relationship management, supply chain management and interorganizational collaboration [9].

Although researchers and practitioners alike are claiming positive effects of eCRM, we still lack appropriate conceptualization and empirical evidence of these effects. In fact, there is no consistent measurement for eCRM success [10], making it difficult to manage and assess eCRM activities. Since eCRM is an IS application [11], the IS success literature can shed some lights on the conceptualization of eCRM success.

IS success has attracted a great deal of research, resulting in several frameworks [12]. For example, Yoon et al. [13] proposed five categories of system success: business profitability, improved decision quality and performance, perceived benefits, level of system usage, and user satisfaction. A widely accepted IS success model is that of DeLone and McLean [14], which defines six constructs associated with IS success: system quality, information quality, system use, individual impact, organizational impact, and user satisfaction. Seddon [15] extended DeLone and McLean's model further, conceptualizing success as a value judgment reflecting the point of view of the stakeholder. Thus IS success is meaningful only in terms of a specific evaluation target and from a particular perspective. Building on previous IS studies, we ground our research in the IS success model, adopting Seddon's [16] approach. As eCRM is a customer-centric strategy, it only makes sense to study its success from the customer's perspective.

Previous research suggests that directly measuring IS success is impractical and perhaps impossible [17], justifying the usage of surrogates. Satisfaction is not just an important determinant of success, but also its proxy. Due to its conceptual closeness and its empirical linkages to the success construct [18], satisfaction is often used as a surrogate measure of IS success in general and the success of e-commerce applications in particular [19]. Compared to other common proxies for success, such as usage and perceived usefulness, satisfaction renders a higher degree of content and construct validity [20]. Gable et al. [21] even argued that satisfaction is an overall measure of success, rather than one of its dimensions. In the context of eCRM, customer satisfaction is an immediate objective that also determines the medium-term goals (e.g., customer retention and loyalty) and subsequently the bottom-line, i.e., profitability. Indeed, satisfaction has been shown to have significant effects on customer loyalty [22], customer retention [23] and profitability [24]. Based on the theoretical and practical arguments presented earlier, we use online customer satisfaction as a proxy of eCRM success in this study.

\section{ECRM satisfaction}

Early IS research focused on end-user satisfaction, modeling it as a function of system, information and service attributes. The proliferation of electronic commerce has blurred the distinction between end-users and online customers, driving the need to account for the mix of technological and marketing elements that become more salient in the Internet environment. The satisfaction of online customers is not solely determined by product and service attributes (as in the marketing literature), but also shaped by the customer's interaction with the system (as in the IS literature). It is hard to discern these sources of satisfaction. Similarly, in studying the role of eCRM in satisfaction formation, it is not possible to separate the effects of marketing activities from those of system features. A holistic view of satisfaction is therefore preferable [25].

Integrating both technological and marketing elements, eCRM covers all aspects of the customer's online 
experience throughout the entire transaction cycle. In the context of e-commerce, Sterne [26] proposes a framework to characterize online customer experience, consisting of three stages: pre-sale, sale, and after-sale interactions. Lu [27] uses this framework to study the effects of ecommerce functionality on satisfaction, demonstrating that eCRM features contribute differently to the satisfaction associated with each transaction stage. Following the same line, Feinberg et al. [28] map the eCRM features of retail websites into the pre-sale, sale and post-sale stages in investigating the relationship between eCRM and satisfaction. The usage of the transaction cycle framework to classify satisfaction is also advocated by Khalifa et al. [29], who investigate the relative contribution of pre-sale, sale and post-sale satisfaction to the formation of overall satisfaction.

In addition to the transaction cycle, the conceptualization of satisfaction should also account for the customer lifecycle. Recent developments in IS satisfaction research highlight the dynamic nature of satisfaction, arguing for a longitudinal approach [30]. Satisfaction formation in the initial stages of usage is more likely to be determined by inner wants, i.e., desires [31, 32]. With experience, the user's beliefs and attitudes are likely to change $[33,34]$. The satisfaction formation is then mainly determined by more concrete expectations [33]. The significance and relative importance of the satisfaction determinants are likely to change depending on the adoption stages, i.e., pre-adoption and postadoption. For eCRM, these adoption stages correspond to the customer lifecycle phases of attraction and retention. The eCRM features that are important for customer attraction are not necessarily the same as those needed for customer retention.

\section{Research model}

The dynamic nature of satisfaction discussed above should be even more salient for novelties such as eCRM. We therefore build a temporal model of satisfaction (Figure 1) distinguishing between two phases of the customer lifecycle: attraction and retention. The attraction phase refers to activities related to getting the attention of potential customers and turning the attention into action, i.e., purchase. As for the retention phase, the eCRM activities focus on keeping the current customers' patronage and developing long-term relationships. From a system perspective, the attraction and retention phases correspond to the pre-usage (at-adoption) and usage (postadoption) stages. Consistent with prior studies [30], we also expect the determinants of satisfaction to differ depending on the adoption stage. Therefore the significance and relative importance of eCRM features for satisfaction formation vary depending on their relevance to the customer lifecycle phase.

Although distinct, satisfaction at attraction and satisfaction at retention are nonetheless significantly related. According to the adaptation level theory [35], the perception of a new experience is regarded as a shift from the individual's prior baseline or reference levels. New cognitions tend to remain close to the prior cognitions (homeostatis), adjusted appropriately for any new positive or negative stimuli [34]. Therefore, initial satisfaction serves as an anchor for later evaluations. Indeed, several studies show that subsequent judgments are likely to be affected by prior judgments, as one tends to reduce the cognitive effort required for performing the re-evaluation [36]. Accordingly, we hypothesize that:

\section{$H_{l}$ : Online customer satisfaction at the attraction} phase is positively related to online customer satisfaction at the retention phase.

While we use the customer lifecycle framework to conceptualize satisfaction, we rely on the transaction cycle to classify eCRM features. Consistent with $\mathrm{Lu}$ and Feinberg et al. [27, 28], our research model identifies three types of eCRM, i.e., pre-purchase, at-purchase, and post-purchase eCRM. The pre-purchase eCRM features are those related with activities that customers perform prior to placing an order, e.g., membership registration and information gathering. In the at-purchase stage,

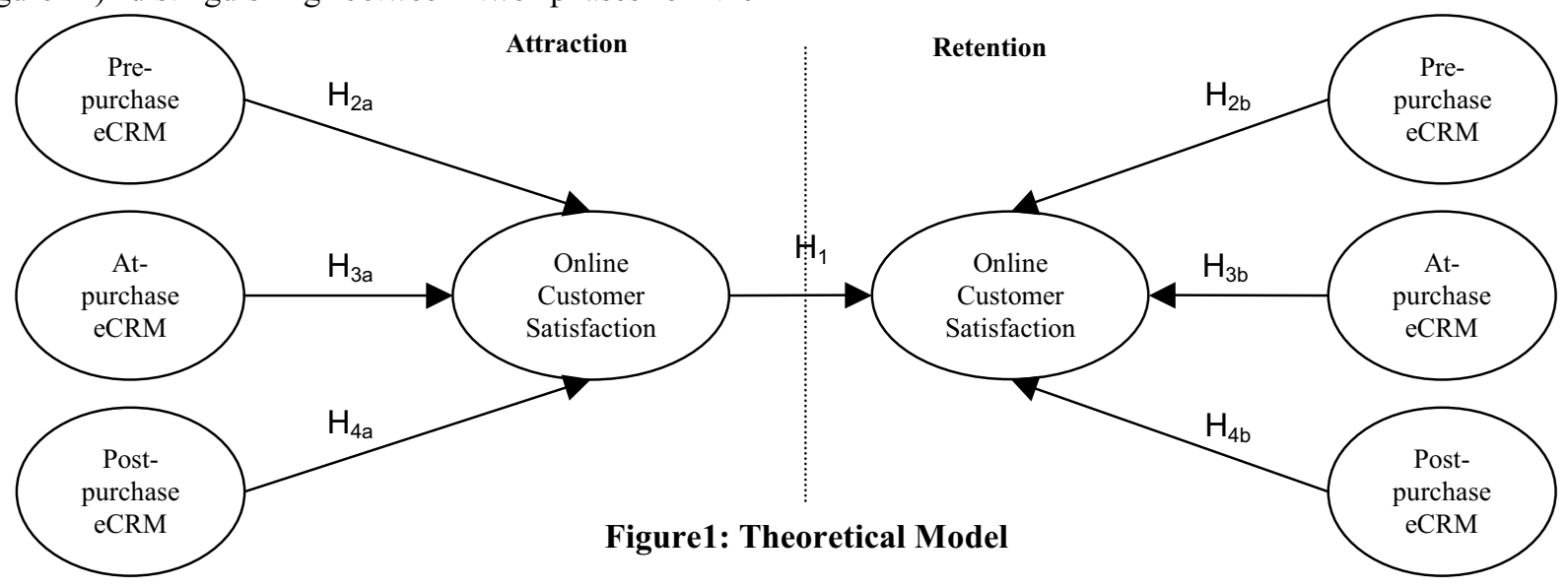


eCRM supports activities associated with product selection and ordering, e.g., comparative shopping and order placement. The post-purchase eCRM features, on the other hand, are those related to after-sale services, e.g., problem solving and order tracking. This classification of eCRM features is consistent with prior research that distinguished between satisfactions at different stages of the transaction cycle. At-purchase satisfaction, for instance, occurs through the personal interaction with the sales personnel and the capability of the selling parties to meet the individual needs of customers [37]. In the online context, however, it is rather the interaction with the website that largely determines the at-purchase satisfaction. During the post-purchase stage, satisfaction with after-sale service is based on the quality of the service itself and the interpersonal experience with the after-sale service personnel [38].

To identify the important eCRM features required for each of the three stages of the transaction cycle, we performed an extensive review of the literature and conducted a belief elicitation with online shoppers (described in the methodology section).

\subsection{Pre-purchase eCRM features}

Site customization: This feature refers to the creation of one-to-one websites that are personalized based on dynamic customer profiles. The ability to adapt the website content to the customer's specific needs, interests and preferences requires the integration of information collected from all touch points.

Customer education: The customer does not necessarily know how to purchase the product, what criteria to consider and how to evaluate them. The guidance that the website offers in this respect helps the customers to select products that better fit their needs.

Alternative channels: Providing several online and offline communication channels enables the customer to pick his/her preferred way of interaction with the firm.

Loyalty program membership: This refers to the provision of plans established around the customers' loyalty drivers, like discounts, special terms, benefits and awards.

Search capabilities: Sophisticated search engines allow the customer to specify multiple criteria for quickly retrieving the desired information.

Alerts: This push technology allows the customer to pre-specify conditions for automatically receiving information about events, new products and promotions.

\subsection{At-purchase eCRM features}

Product customization: This refers to order building as opposed to order taking. The customer can select alternative components for customizing the product to his/her specific needs.

Payment methods: This is another form of customization that enables the customer to choose a preferred payment method, e.g., credit card, cash on delivery, and electronic cash.

Purchase conditions: Contractual conditions such as delivery, service, return policies, and guarantee are clearly stated and easily accessible.

Comparative shopping: The customer can compare alternative products on selected attributes.

Dynamic pricing: The product prices are customized based on the customer status and the order characteristics (e.g., quantities, product mix).

\subsection{Post-purchase eCRM features}

Online sale of spare parts: The availability of spare parts online is an important element of after sales service.

Problem solving: This feature refers to the provision of assistance to help the customer become more active and more efficient in solving problems. It can take several forms, some passive, e.g., online manuals, FAQs and others more interactive, e.g., experts systems, web agents.

Feedback channels: These are means by which a customer gives feedback and evaluations about the service or product. They include online surveys, email and discussion forums.

Order tracking: This service enables customers to actively follow their orders instead of passively waiting for information.

Online community: This refers to providing the customers with an online space where they can interact with each other, share experiences, discuss products and provide value to each other.

Web center: This serves the role of a call center, but through the Web.

All eCRM features discussed above constitute system, information or service quality attributes. Based on the IS success model, such attributes have significant effects on satisfaction $[14,39,40]$. We therefore hypothesize that:

\section{$H_{2 a(b)}$ : Pre-purchase eCRM has a positive effect on online customer satisfaction at the attraction (retention) phase. \\ $H_{3 a(b)}:$ At-purchase eCRM has a positive effect on online customer satisfaction at the attraction (retention) phase. \\ $H_{4 a(b)}$ : Post-purchase eCRM has a positive effect on online customer satisfaction at the attraction (retention) phase.}

Although we expect all eCRM features to have significant effects, we anticipate the magnitude of these 
effects to vary from the attraction phase to the retention phase. This temporal variation reflects the changing needs of customer from phase to phase. Furthermore, the beliefs and attitudes of customers may change with time as they gain first-hand experience with the eCRM system [41].

\section{Methodology}

The temporal research model is validated through a longitudinal online survey study. Pitkow and Recker [42] present the advantages of online surveys. The methodology consisted of three stages: 1) belief elicitation, 2) survey of the beliefs and satisfaction of online customers at the attraction phase, and 3) survey of the beliefs and satisfaction of the same customers at the retention phase.

\subsection{Belief elicitation}

To develop formative items for the constructs, "prepurchase eCRM", "at-purchase eCRM" and "postpurchase eCRM", we examined the literature and conducted a belief elicitation procedure. Forty online shoppers were selected randomly from the customer base of an Internet retailer of computer hardware. The selected subjects were invited to participate in a focus group discussion. They were divided into four groups of 10 individuals each. In the focus group discussions, the participants were asked to identify important eCRM features that influenced their satisfaction with online shopping and to categorize them under pre-purchase eCRM, at-purchase eCRM and post-purchase eCRM. Based on the literature review and the results of the belief elicitation process, we compiled a list of 17 formative items presented in Table 2.

\subsection{Survey study}

The survey instrument consists of reflective items for the "online customer satisfaction" construct and formative items developed through the belief elicitation process for the remaining constructs. The reflective items were validated with the card sorting procedure suggested by Moore and Benbasat [43]. All items were measured on a 7-point Likert scale with values ranging from $1=$ strongly disagree to $7=$ strongly agree. The resulting survey was then administered electronically to online shoppers of several Internet retailers of computer hardware, twice. The first survey (attraction phase survey) was administered to the new online customers, upon their membership registration. The second survey (retention phase survey) was administered to the respondents of the first survey six months later. A total of 705 customers answered both surveys. Table 1 presents the demographic information of the respondents.

Table 1: Demographic Information

\begin{tabular}{|l|l|c|}
\hline \multicolumn{2}{|c|}{ Category } & $\%$ \\
\hline \multirow{4}{*}{ Age } & Less than 20 years & 1 \\
\cline { 2 - 3 } & $20-35$ years & 59 \\
\cline { 2 - 3 } & $35-50$ years & 24 \\
\cline { 2 - 3 } & Greater than 50 years & 16 \\
\hline Education & High School & 17 \\
\cline { 2 - 3 } & Bachelor & 54 \\
\cline { 2 - 3 } & Master & 26 \\
\cline { 2 - 3 } & Higher than Master & 3 \\
\hline \multirow{4}{*}{ Annual Income } & Less than 20,000 USD & 14 \\
\cline { 2 - 3 } & 20,000 - 35,000 USD & 41 \\
\cline { 2 - 3 } & $35,000-50,000$ USD & 34 \\
\cline { 2 - 3 } & Greater than 50,000 USD & 11 \\
\hline \multirow{4}{*}{$\begin{array}{l}\text { Number of Purchases } \\
\text { within 6 Months }\end{array}$} & 1 purchase & 16 \\
\cline { 2 - 3 } & 2 purchases & 43 \\
\cline { 2 - 3 } & 3 purchases & 32 \\
\cline { 2 - 3 } & Over 3 purchases & 9 \\
\hline
\end{tabular}

Although we rely on the same respondents for the dependent and independent variables, the longitudinal research design reduces potential common method bias. Since not all variables are measured at the same time (i.e., attraction satisfaction, retention satisfaction), the risk of the respondents giving artificially consistent responses is reduced.

\subsection{Data analysis}

The data analysis was done in a holistic manner using the Partial Least Squares procedure (PLS), because it allows for the simultaneous usage of reflective and formative measurements and is able to model latent constructs under conditions of non-normality and small to medium sample sizes [44]. We conducted tests of significance for all paths using the bootstrap re-sampling procedure [45] and the standard approach for evaluation that requires path loadings from construct to measures to exceed 0.70. For checking internal consistency of the reflective measures, we relied on composite reliability measures ( $\rho)$ as suggested by Chin [46] and on the average variance extracted (AVE) as suggested by Fornell and Larcker [47]. We tested the discriminant validity by comparing the square root of the AVE for a particular construct to its correlations with the other constructs [48] and by examining cross-loadings of the constructs. In contrast, formative measurement assumes causality 
flowing from the measures to the latent construct, where the indicators jointly determine the conceptual and empirical meaning of the emergent first-order factor [49]. Chin [46] recommends in this particular case to use the weight of each item to assess how much it contributes to the overall factor.

\section{Results and discussion}

Table 2 presents the weights of the formative measures and the loadings of the reflective measures to their respective constructs along with standard errors and tstatistics. All reflective items are significant at the $99 \%$ level with high loadings (all above 0.70 and most above 0.80 ), therefore demonstrating convergent validity. The composite reliability scores $(\rho)$ of all constructs are higher than the recommended value of 0.80 , indicating internal consistency [50]. For formative items, the magnitude and significance of the weight indicate the importance of the contribution of the associated variable to customer satisfaction.

Table 2: Measurement Model

\begin{tabular}{|c|c|c|c|c|c|}
\hline Constructs & Items & Weights & Loading & Std. Error & T-Statistics \\
\hline \multirow{6}{*}{$\begin{array}{l}\text { Pre-Purchase eCRM } \\
\text { (Attraction Stage) }\end{array}$} & Consumer education & 0.419 & & 0.0579 & 7.2437 \\
\hline & Search capabilities & 0.327 & & 0.0798 & 4.1018 \\
\hline & Site customization & 0.295 & & 0.0452 & 6.5300 \\
\hline & Alternative channels & 0.295 & & 0.0742 & 3.9604 \\
\hline & Loyalty program membership & 0.124 & & 0.0429 & 2.8997 \\
\hline & Alerts & 0.011 & & 0.0380 & 0.2763 \\
\hline \multirow{5}{*}{$\begin{array}{l}\text { At-Purchase eCRM } \\
\text { (Attraction Stage) }\end{array}$} & Product customization & 0.779 & & 0.0419 & 18.6002 \\
\hline & Comparative shopping & 0.288 & & 0.0709 & 4.0556 \\
\hline & Dynamic pricing & 0.240 & & 0.0620 & 3.8745 \\
\hline & Payment methods & 0.190 & & 0.0519 & 3.6619 \\
\hline & Purchase conditions & 0.144 & & 0.0691 & 2.0788 \\
\hline \multirow{6}{*}{$\begin{array}{c}\text { Post-Purchase eCRM } \\
\text { (Attraction Stage) }\end{array}$} & Problem solving & 0.604 & & 0.0710 & 8.5174 \\
\hline & Order tracking & 0.369 & & 0.0675 & 5.4630 \\
\hline & Feedback channel & 0.310 & & 0.0871 & 3.5549 \\
\hline & Web center & 0.244 & & 0.0777 & 3.1410 \\
\hline & Online community & 0.214 & & 0.0798 & 2.6862 \\
\hline & Online Purchase of spare parts & 0.193 & & 0.0804 & 2.4041 \\
\hline \multirow{3}{*}{$\begin{array}{c}\text { Online Shopping } \\
\text { Satisfaction } \\
\text { (Attraction Stage) } \\
\rho=0.96\end{array}$} & Satisfaction 1 & & 0.947 & 0.0058 & 162.34 \\
\hline & Satisfaction 2 & & 0.942 & 0.0089 & 106.03 \\
\hline & Satisfaction 3 & & 0.967 & 0.0029 & 328.49 \\
\hline \multirow{6}{*}{$\begin{array}{l}\text { Pre-Purchase eCRM } \\
\text { (Retention Stage) }\end{array}$} & Alerts & 0.429 & & 0.0480 & 8.9436 \\
\hline & Search capabilities & 0.369 & & 0.0530 & 6.9579 \\
\hline & Site customization & 0.316 & & 0.0588 & 5.3659 \\
\hline & Consumer education & 0.199 & & 0.0462 & 4.3030 \\
\hline & Alternative channels & 0.137 & & 0.0555 & 2.4608 \\
\hline & Loyalty program membership & 0.127 & & 0.0522 & 2.4272 \\
\hline \multirow{5}{*}{$\begin{array}{c}\text { At-Purchase eCRM } \\
\text { (Retention Stage) }\end{array}$} & Product customization & 0.568 & & 0.0596 & 9.5359 \\
\hline & Comparative shopping & 0.328 & & 0.0789 & 4.1591 \\
\hline & Dynamic pricing & 0.292 & & 0.1009 & 2.8947 \\
\hline & Payment methods & 0.258 & & 0.0789 & 3.2638 \\
\hline & Purchase conditions & 0.200 & & 0.1206 & 1.6556 \\
\hline \multirow{6}{*}{$\begin{array}{c}\text { Post-Purchase eCRM } \\
\text { (Retention Stage) }\end{array}$} & Problem solving & 0.448 & & 0.0474 & 9.4349 \\
\hline & Web center & 0.327 & & 0.0407 & 8.0488 \\
\hline & Order tracking & 0.303 & & 0.0437 & 6.9351 \\
\hline & Online community & 0.173 & & 0.0469 & 3.6769 \\
\hline & Online purchase of spare parts & 0.125 & & 0.0407 & 3.0619 \\
\hline & Feedback channel & 0.095 & & 0.0299 & 3.1741 \\
\hline \multirow{3}{*}{$\begin{array}{c}\text { Online Shopping } \\
\text { Satisfaction } \\
\text { (Retention Stage) } \\
\rho=0.87\end{array}$} & \begin{tabular}{|l|} 
Satisfaction 1 \\
\end{tabular} & & 0.927 & 0.0057 & 163.02 \\
\hline & Satisfaction 2 & & 0.868 & 0.0131 & 66.51 \\
\hline & Satisfaction 3 & & 0.717 & 0.0263 & 27.44 \\
\hline
\end{tabular}


The square roots of the AVE scores (0.952 for "attraction satisfaction" and 0.844 for "retention satisfaction") are all higher than the correlations between these two constructs $(0.511)$, demonstrating discriminant validity. Furthermore, all items loaded higher on their respective constructs than on others, providing additional evidence for discriminant validity. These results support the distinction between "attraction satisfaction" and "retention satisfaction", justifying the usage of a temporal model for explaining satisfaction formation.

Figure 2 presents the results of PLS analysis of the structural model, including the overall explanatory power $\left(\mathrm{R}^{2}\right.$ is indicated below each dependent construct) and path coefficients. The model explains $53.4 \%$ of the variance in online customer satisfaction at the attraction phase and $67.7 \%$ of satisfaction at the retention phase, indicating good explanatory power. Furthermore, all path coefficients are significant at the $99 \%$ level, providing strong support for all the hypothesized relationships.

At the attraction phase, all three determinants of overall satisfaction (i.e., pre-purchase, at-purchase and post-purchase eCRM) are significant, but with different magnitudes. Pre-purchase eCRM, with a path coefficient of 0.50 , is the dominant driver of online customer satisfaction. One plausible explanation of the importance of pre-purchase eCRM at the attraction phase is that at this phase potential customers are mainly concerned with the decision of whether or not to become a customer and new customers are probably still evaluating their decision. Therefore, pre-purchase eCRM features for educating the customers, providing resources for making informed decisions (e.g., search capabilities) and facilitating the decision-making process (e.g., site customization, alternative channels) are more salient. These features aim at reducing the risk for the customers and gaining their trust. An additional explanation for the dominance of the pre-purchase eCRM features at the attraction phase is that new customers are not yet sufficiently familiar with the atpurchase and post-purchase eCRM features to appreciate their importance.

At the retention phase, pre-purchase eCRM loses its importance (path coefficient reduced from 0.5 to 0.11 ), while post-purchase eCRM becomes dominant (path coefficient increasing from 0.118 to 0.645 ). A possible interpretation of this result is that with repeat purchase, the pre-purchase and at-purchase eCRM activities become familiar and routine. They are taken for granted. The postpurchase eCRM activities, on the other hand, remain contingent on emergent needs rising from the customer's use of the product. Problem solving capabilities, access to required knowledge and interactions with web center representatives or other customers help to satisfy these dynamic needs. The change in the relative importance of the determinants of satisfaction from the attraction phase to the retention phase provides additional support for the temporal conceptualization of satisfaction as well as for the usage of the transaction cycle framework to categorize eCRM features.

The significance of the relationship between attraction satisfaction and retention satisfaction confirms the claim that prior judgments influence subsequent ones [51]. However, compared with the significance and magnitude of the other determinants, the relatively small magnitude of the effect of attraction satisfaction on retention satisfaction (0.101) highlights the necessity of a temporal model.

The examination of the weights of the formative measures of the satisfaction determinants reveals the relative importance of specific eCRM features in satisfaction formation. At the attraction phase, customer education is the dominant pre-purchase eCRM feature with a weight of 0.419 . Shopping for a computer is not an easy task for the average customer. A web site that provides guidance on how to shop for a computer helps the customer to make a better purchase decision and to therefore be happier with the outcome. Also, education balances the customer's skills and the challenges of online shopping, leading to a smoother and more enjoyable online experience [52]. The second important prepurchase eCRM variable is the web site's search capabilities with a weight of 0.327 . This feature is especially important when the customer has to consider a large number of criteria in selecting the product. Its importance highlights the necessity to support the

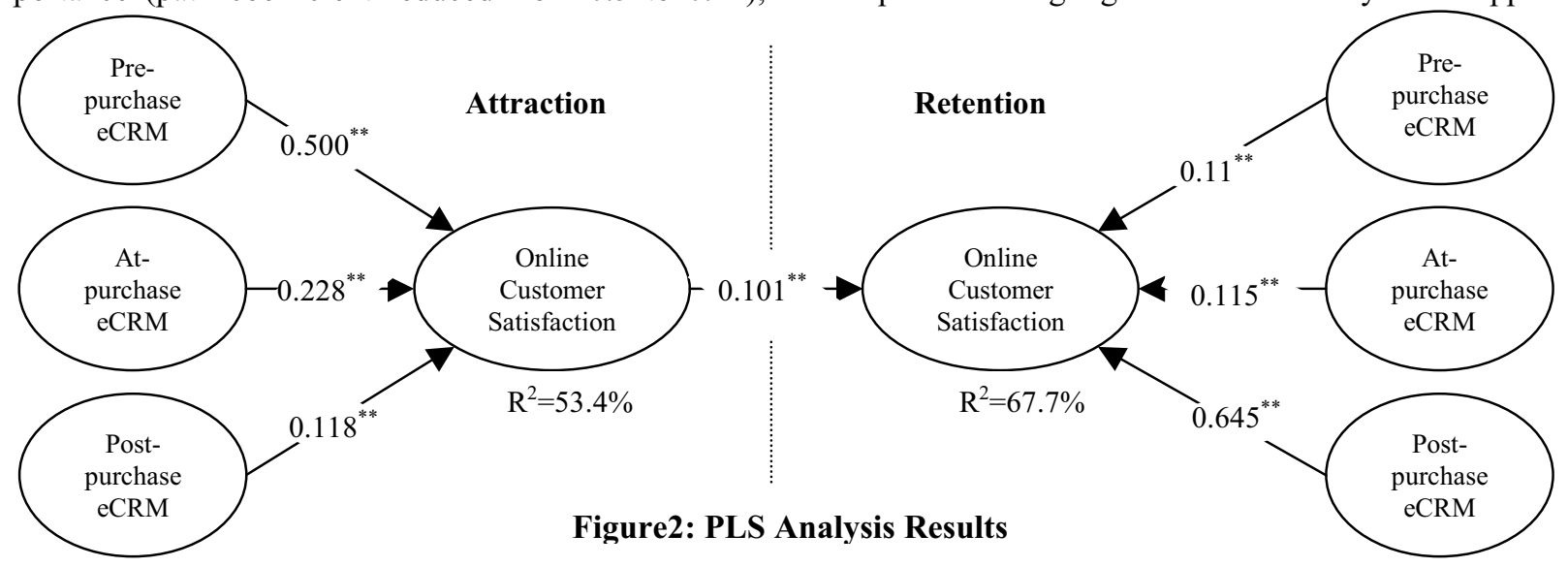


customer's decision-making process in the attraction phase. Of similar importance is website customization (0.295). Its magnitude highlights the importance of oneto-one web sites that are constantly customized or even personalized based on a dynamic customer profile. One of the advantages of eCRM is the customization of the volume of information available to the browsing customer [28]. Such customization enables the customer to be more efficient and to make better-informed decisions. Offering alternative channels, with an equal weight to site customization (0.295), is also perceived to be important. Alternative channels can be both online and offline. Although the Internet retailer may favor some channels for their efficiency, it is important to leave it to customers to choose their preferred channel, as this is another form of customization. Loyalty program membership, although not perceived to be as important as the other pre-purchase eCRM features, is nevertheless significant with a weight of 0.124. An increasing number of Internet vendors encourage their customers to enroll into loyalty programs by providing them with attractive membership perks, e.g., special terms, discounts, gifts, etc. Such programs enable the vendor to learn more about the online behavior of registered members (e.g., click stream analysis) and hence achieve better customization. The only pre-purchase eCRM feature that is not significant is alerts. In fact, out of all features identified through the belief elicitation process alerts is the only one that does not have a significant effect on satisfaction. Furthermore, its lack of significance is limited to the attraction phase only. In fact, it becomes the most important pre-purchase eCRM feature at the retention phase. A possible explanation for these results is that alerts are more useful for repurchase activities rather than for making the initial decision of becoming a customer.

For the at-purchase stage, product customization emerges as the most important driver of satisfaction with a weight of 0.779 . This finding is consistent with the essence of eCRM: maintaining a one-to-one relationship with the customer by among other things offering a solution that suits the customer's specific needs rather than a standard product. This can be achieved by enabling order building instead of order taking. In the context of computer products, some websites, e.g., Dell's, assist the customers in building unique computer solutions by allowing them to select the components that better serve their needs without restricting their choices to standard computer packages. The second important variable is comparative shopping with a weight of 0.288 . The importance of this eCRM capability is especially salient for computer products, where several alternatives need to be compared in terms of multiple criteria. The respondents also perceive dynamic pricing as a significant eCRM satisfaction factor with a weight of 0.24 . This result reemphasizes the importance of extending customization from product selection to pricing as well. Next in terms of importance are payment methods and purchase conditions with weights of 0.19 and 0.144 respectively.

For the post-purchase stage, problem solving is the strongest satisfaction factor with a weight of 0.604 . The magnitude of the problem solving effect highlights the necessity to provide immediate solutions to customers' problems and suggests the need for real-time interactivity. While some simple problems can be solved with information provided by online manuals and FAQs, more complex problems may require expert systems or synchronous interactions with customer service personnel or even other customers. The second important variable is order tracking with a weight of 0.369 . With this feature customers do not passively wait to be informed of the status of their orders and can actively seek the information online. Such capability is at the essence of CRM in that it helps to strengthen the relationship between the customer and the merchant by making it less passive and more active. Next in magnitude is feedback channel with a weight of 0.31 , highlighting the need for two-way communications. The importance of providing multiple channels of interaction is reemphasized in the significance of web center (0.244) and online community (0.214). While web centers can provide personalized attention and hence contribute to one-to-one marketing, online communities play a critical role in implementing many-tomany marketing, where the customers are involved in providing value to each other. Through an online community, the customers can share experiences and exchange valuable information for solving problems and making a more effective use of the product. Finally, online purchase of spare parts is also perceived as a significant factor with a weight of 0.193 .

Although the temporal model of satisfaction demonstrates a change in the magnitude of the effects of the three categories of eCRM, i.e., pre-purchase, atpurchase and post-purchase, the relative importance of specific eCRM features within each category does not change much from the attraction phase to the retention phase. There are, however, a few exceptions, notably, the decrease in importance of customer education and the change in significance of alerts. While customer education is the most important variable for pre-purchase eCRM at the attraction phase, it is of moderate importance in the retention phase. This is an expected result. Customer education is essential for the initial purchase decision, but routine for repurchase. Alerts, on the other hand, are not significant in the attraction phase where the customer may not be confident about what to expect from the vendor. With experience, the customer forms more concrete expectations and can therefore define better his/her requirements in setting up the alerts. 


\section{Conclusion}

In this research, we investigate the relationship between eCRM and an important surrogate of eCRM success: online customer satisfaction. More specifically, we develop, operationalize and empirically test a temporal model explaining the relationship between three categories of eCRM (i.e., pre-purchase, at-purchase and post-purchase eCRM) and online customer satisfaction at two phases of the customer lifecycle, i.e., attraction and retention. Our research presents important theoretical and practical contributions. On the theoretical side, we demonstrate the necessity of the temporal conceptualization of online customer satisfaction in order to account for the variability of the satisfaction drivers from the attraction phase to the retention phase. We also show the suitability of the transaction cycle framework for categorizing eCRM. The results of a longitudinal survey of the online customers of hardware retailers provided strong support for the model and revealed the dominant role of pre-purchase eCRM in satisfaction formation at the attraction phase and the prevalence of post-purchase eCRM at the retention phase. On the practical side, a belief elicitation process identified specific features for each of the three eCRM categories. The survey results elucidated the relative importance of these features in satisfaction formation, giving insights to practitioners. The practical implications can be summarized as three paradigm shifts. The significance and magnitude of the effects of product customization, website customization and dynamic pricing reflect the perceived importance of eCRM activities that are intended to support the one-toone paradigm shift: transforming the relationship between the firm and the customer from a one-to-many mode into a one-to-one mode. Other eCRM drivers of customer satisfaction include alerts, search capabilities, order tracking and problem solving. They represent another transformation of the relationship between the firm and the customer: from passive to active. Another significant variable, i.e., online community, is intended for yet another paradigm shift: many-to-many marketing, where the customers are involved in providing value to each other.

In future research, other proxies of eCRM success (e.g., continued usage: repurchase, firm profitability) should be studied. Of particular interest is the mediating role of satisfaction. In fact, satisfaction is considered to be an immediate goal of eCRM that is assumed to determine the medium-term goals (e.g., customer retention and loyalty) and subsequently firm performance, e.g., profitability. These complex relationships require further investigation.

\section{References}

[1] H. Rosenbaum and B.Y. Huang, A framework for web-based ecommerce customer relationship management. in Proceedings of the 8th AMCIS Conference. 2002.

[2] M. Apicella, Solid CRM is difficult, but not impossible, in Info World. 2001. p. 55-56.

[3] K. Melymuka, You can avoid CRM's pitfalls, in Computerworld. 2002.

[4] A. Bednarz, Gartner: CRM deployment plans holding steady. 2001, http://www.computerworld.com.

[5] R. Feinberg and R. Kadam, E-CRM Web service attributes as determinants of customer satisfaction with retail Web sites. International Journal of Service Industry Management, 2002. 13(5), pp. 432-451.

[6] V. McKinney, K. Yoon, and F. Zahedi, The measurement of web-customer satisfaction: an expectation and disconfirmation approach. Information Systems Research, 2002. 13(3), pp. 296315.

[7] J. Anton and M. Hoeck, e-Business Customer Service. 2002, Santa Monica, CA: The Anton Press.

[8] Y.P. Sheng. A business model and framework for electronic customer relationship management. in Proceedings of the 8th AMCIS Conference. 2002.

[9] A. Zornes and M. Gotta, Web \& collaboration strategies. 2001, META Group Inc.

[10] D.L. Goodhue, B.H. Wixom, and H.J. Watson, Realizing business benefits through CRM: hitting the right target in the right way. MIS Quarterly Executive, 2002. 1(2), pp. 79-94.

[11] N.C. Romano Jr. and J. Fjermestad, Electronic commerce customer relationship management: An assessment of research. International Journal of Electronic Commerce, 2001. 6(2), pp. 61-113.

[12] E.J. Garrity and G.L. Sander, Information Systems Success Measurement. 1998, Hershey: Idea Group Publishing.

[13] Y. Yoon, T. Guimaraes, and Q. O'Neal, Exploring the factors associated with expert systems success. MIS Quarterly, 1995. 19(1), pp. 83-106.

[14] W.H. DeLone and E.R. McLean, Information systems success: the quest for the dependent variable. Information Systems Reseaerch, 1992. 3(1), pp. 60-95.

[15] P.B. Seddon, A respecification and extension of the DeLone and McLean model of IS success. Information Systems Reseaerch, 1997. 8(3), pp. 240-253.

[16] P.B. Seddon, S. Staples, R. Patnayakuni, and M. Bowtell, Dimensions of information systems success. Communications of AIS, 1999. 2(Article 20).

[17] D.F. Galletta and A.L. Lederer, Come cautions on the measurement of user information satisfaction. Decision Sciences, 1989. 20, pp. 419-437.

[18] J.B. Bailey and S.W. Pearson, Development of a tool for measuring and analyzing computer user satisfaction. Management Science, 1983. 29(5), pp. 530-545.

[19] H.W. Kim, G.H. Lee, and S.L. Pan. Exploring the critical success factors for customer relationship management and electronic customer relationship management systems. in Twenty-Third International Conference on Information Systems. 2002.

[20] P. Ein-Dor and E. Segev, Organizational context and the success of management information systems. Management Science, 1978. 24(10), pp. 1064-1077. 
[21] G.G. Gable, D. Sedera, and T.Z. Chan. Enterprise systems success: a measurement model. in Twenty-Fourth International Conference on Information Systems. 2003.

[22] R.E. Anderson and S.S. Srinivasan, E-satisfaction and Eloyalty: a contingency framework. Psychology \& Marketing, 2003. 20(2), pp. 123-138.

[23] R.T. Rust and A.J. Zahorik, Customer satisfaction, customer retention, and market share. Journal of Retailing, 1993. 69, pp. 193-215.

[24] C. Homburg, W.D. Hoyer, and M. Fassnacht, Service orientation of a retailer's business strategy: dimensions, antecedents, and performance outcomes. Journal of Marketing, 2002. 66(4), pp. 86-101.

[25] J.B. Rust, J.J. Inman, and A. Zahorik, What you don't know about customer perceived quality: the role of customer expectation distributions. Management Science, 1999. 18(1), pp. 77-92.

[26] J. Sterne, Customer service on the Internet. 1996, New York: John Wiley and Sons.

[27] J. Lu, A model for evaluating e-commerce based on cost/benefit and customer satisfaction. Information Systems Frontiers, 2003. 5(3), pp. 265-277.

[28] R.A. Feinberg, R. Kadam, L. Hokama, and I. Kim, The state of electronic customer relationship management in retailing. International Journal of Retail \& Distribution Management, 2002. 30(10), pp. 470 - 481.

[29] M. Khalifa, M. Limayem, and V. Liu, Online consumer stickiness: a longitudinal study. Journal of Global Information Management, 2002. 10(3), pp. 1-15.

[30] M. Khalifa and V. Liu, Determinants of satisfaction at different adoption stages of Internet-based services. Journal of AIS, 2003. 4(5), pp. 206-232.

[31] A. Bhattacherjee, Direct experience and attitude-behavior consistency. MIS Quarterly, 2001. 25(3), pp. 351-37-.

[32] M. Khalifa and V. Liu, Satisfaction with internet-based services: the role of expectations and desires. International Journal of Electronic Commerce, 2003. 7(2), pp. 31-50.

[33] E. Karahanna, D.W. Straub, and N.L. Chervany, Information technology adoption across time: a cross-sectional comparison of pre-adoption and post-adoption beliefs. MIS Quarterly, 1999. 23(2), pp. 183-213.

[34] A. Bhattacherjee and G. Premkumar, Understanding changes in belief and attitude toward information technology usage: a theoretical model and longitudinal test. MIS Quarterly, 2004. 28(2), pp. 229-254.

[35] H. Helson, Adaptation-Level Theory: An Experimental and Systematic Approach to Behavior. 1964, New York: Harper \& Row.

[36] S.T. Fiske and S.L. Neuberg, A continuum of impression formation, from category-based to individual processes: influences of information and motivation on attention and interpretation, in Advanced in Experimental Social Psychology, M.P. Zanna, Editor. 1990, Academic Press: New York, NY. p. $1-74$.

[37] C. Homburg and A. Giering, Personal characteristics as moderators of the relationship between customer satisfaction and loyalty: an empirical analysis. Psychology \& Marketing, 2001. 18(1), pp. 43-66.

[38] L. Crosby, K. Evan, and D. Cowles, Relationship quality in services selling : An interpersonal influence perspective. Journal of Marketing, 1990. 54(3), pp. 68-81.
[39] S. Devaraj, M. Fan, and R. Kohli, Antecedents of B2C Channel Satisfaction and Preference: Validating e-Commerce Metrics. Information Systems Research, 2002. 13(3), pp. 316333.

[40] L.F. Pitt, R.T. Watson, and C.B. Kavan, Service quality: a measure of information effectiveness. MIS Quarterly, 1995. 19(2), pp. 179-187.

[41] S. Balasubramanian, P. Konana, and N.M. Menon, Customer satisfaction in virtual environments: a survey of online investing. Management Science, 2003. 49(7), pp. 871-889.

[42] J.E. Pitkow and M.M. Recker, Using the Web as a Survey Tool: Results from the Second WWW User Survey. Journal of Computer Networks and ISDN Systems, 1995. 27(6), pp. 809822.

[43] G.C. Moore and I. Benbasat, Development of an instrument to measure the perceptions of adopting and information technology innovation. Information Systems Reseaerch, 1991. 2(3), pp. 192-222.

[44] W.W. Chin, B.L. Marcolin, and P.R. Newsted, A Partial Least Squares Latent Variable Modeling Approach for Measuring Interaction Effects: Results from a Monte Carlo Simulation Study and an Electronic-Mail Emotion / Adoption Study. Information Systems Research, 2003. 14(2), pp. 189-217. [45] W. Cotteman and J. Senn, Challenges and Strategies for Research in Systems Development. 1992, Chichester: Wiley.

[46] W.W. Chin, The Partial Least Squares Approach for Structural Equation Modeling. Lawrence Erlbaum Associates, 1998, pp. 295-336.

[47] C. Fornell and D. Larcker, Evaluating structural equation models with unobservable variables and measurement error. Journal of Marketing Research, 1981. 18, pp. 39-50.

[48] C. Fornell and D. Larcker, A Second Generation of Multivariate Analysis: Classification of Methods and Implications for Marketing Research, in Review of Marketing, M.J. Houston, Editor. 1987, American Marketing Association: Chicago. p. 407-450.

[49] K. Bollen, Structural Equations with Latent Variables. 1989, New York: Wiley.

[50] J.C. Nunnally, Psychometric Theory. 1978, New York: McGraw Hill.

[51] R.N. Bolton, A dynamic model of the duration of the customer's relationship with a continuous service provider: the role of satisfaction. Management Science, 1998. 17(1), pp. 4565.

[52] D.L. Hoffman and T.P. Novak, Marketing in Hypermedia Computer-Mediated Environments: Conceptual Foundations. Journal of Marketing, 1996. 60(3), pp. 50-68. 